\title{
Leitura sobre lgualdade: considerações sobre as oscilações de um conceito na perspectiva de alguns autores do século XVII ao XX
}

\author{
Lectures on Equality: considerations about the \\ oscillations of a concept in the perspective of \\ several authors from the XVII to XX centuries
}

\section{José D'Assunção Barros}

\section{Resumo}

Este artigo busca elaborar uma visão comparada sobre algumas das leituras sobre a noção de igualdade que foram desenvolvidas por autores distintos do final do século XVII à primeira metade do século XX. Alguns autores específicos foram escolhidos para esta finalidade, embora não sejam certamente os únicos que trouxeram contribuições importantes para o desenvolvimento do conceito nas ciências humanas e no imaginário político. O objetivo é o de mostrar como as diversas leituras sobre as ideias de igualdade e desigualdade, desenvolvidas por estes autores, contrastam entre si e remetem a matrizes de pensamento distintas. O exame dos pensamentos destes autores, relacionados à ideia de igualdade, permite também atentar para alguns dos modelos clássicos relacionados a esta discussão.

\section{Palavras-chave}

Igualdade; Desigualdade; Diferença; Movimentos Políticos; Imaginário Político.

\begin{abstract}
This article seeks to elaborate a comparative view on some of the lectures about the notion of equality that were developed by different authors from the end of the XVII century and the first half of the twentieth century. Specifically several authors were chosen to reach this objective, although they are not, the only ones that bring important contributions for the development of the concept of equality in the human sciences and in the political imaginary. The objective of this paper is to show how the various lectures about the ideas of equality and inequality developed by these authors, contrast among themselves and are related to different schools of thought. The analysis of these authors' thoughts concerning the idea of equality permits, at the same time, evaluate some of classic models related to this discussion.
\end{abstract}

\section{Keywords}

Equality; Inequality; Difference; Political Movements; Political Imaginary. 


\section{A Igualdade no mundo laico: os primórdios da matriz liberal}

Na história contemporânea, é com as sociedades que emergem da derrocada do chamado Antigo Regime que a ideia de "igualdade comum a todos os homens" consegue transpor definitivamente o espaço religioso para conquistar o espaço político e o espaço jurídico, e é nesta parte da história das ideias relacionadas à noção de igualdade que iremos nos concentrar neste artigo. Inicialmente, o que nos interessa é chamar atenção para o fato de que o deslocamento da noção de igualdade no interior dos âmbitos do pensamento político, jurídico e social não se fez em uma única direção. Trata-se de um deslocamento que tem comportado variadas trajetórias internas, e tem produzido no decurso de sua história diversificados modelos de pensamento sobre a igualdade. Alguns autores foram escolhidos para revelar um contraste possível entre diferentes leituras da desigualdade, como Hobbes, Locke, Rousseau e outros. Certamente que vários outros autores apresentaram importantíssimas discussões sobre a noção de igualdade no decurso da história das ideias. Podemos lembrar Kant, Proudhon, Marx, Stuart Mill e John Rawls, entre outros. Os autores escolhidos, de todo modo, fornecem bons indicadores dos possíveis contrastes que pode permear as reflexões sobre a igualdade e desigualdade humana, e são úteis para examinar as oscilações do contexto.

Apenas para iniciar com dois exemplos basilares entre as filosofias préiluministas e iluministas, será oportuno começar nossa reflexão com o exame de dois nomes angulares - o de John Locke (1632-1704) e o de Jean-Jacques Rousseau (1712-1778). Estes dois autores são úteis para um contraste inicial porque partem, ambos, de uma imaginação inicial sobre a origem da desigualdade humana e da consequente necessidade da busca de uma possível igualdade social nos ambientes sociais e políticos produzidos pela vida dos seres humanos em coletividades dotadas de certa complexidade. Em oposição a Hobbes (1588-1679), teórico do poder absoluto que vaticinara que no seu estado essencial "o homem é o lobo do homem", Locke e Rousseau partem ambos da ideia de que no estado original de natureza os homens eram felizes e iguais ${ }^{1}$. Mas a partir daí os dois autores evoluem para posições distintas que iriam se tornar matriciais para dois campos conceituais bem diferenciados.

John Locke (1632-1704) escreve algumas de suas principais obras na Inglaterra do final do século XVII. Sua vida se desenvolve em uma Inglaterra que havia conhecido, entre os anos 1642 e 1648, duas grandes guerras civis (1642-1646 e 1648). Nestes conflitos, o ambiente social inglês viu-se dividido diante de uma luta política que estabelecera a oposição entre setores sociais que apoiaram politicamente a realeza (a nobreza da província, também conhecida como gentry, a hierarquia da igreja anglicana e os camponeses), e setores que apoiaram o parlamento (classe média urbana, grandes mercadores e setores da grande aristocracia). Fatores religiosos, envolvendo anglicanos, presbiterianos, católicos e independentes também

\footnotetext{
${ }^{1}$ Hobbes, ao contrário, define este estado de natureza primordial como um "estado de guerra" assaltado pela insegurança e pela violência (HOBBES, 1974, p.79).
} 
adentram este confronto, não devendo ser esquecidos os inúmeros grupos de protestantismo radical, tão bem estudados por Christopher Hills em seu livro $O$ Mundo de Ponta-Cabeça (1987). O estabelecimento do Commonwealth entre 1649 e 1660, após a decapitação do rei em 1649, constitui o acontecimento político central para o qual todos estes processos derivaram. Depois deste período, estabelece-se a restauração do poder monárquico com Carlos II, mas já matizada por um diálogo efetivo com as forças que haviam apoiado o parlamento no período de conturbação política e de instituição do governo comandado por Cromwell. Novas tensões conduziriam aos acontecimentos que ficariam conhecidos como "Revolução Gloriosa" (1688). É neste conturbado ambiente político atravessado por duas grandes revoltas contra a realeza e suas tentativas de restauração, conduzindo a um acordo possível entre os diversos setores que detinham poderes políticos e econômicos, que John Locke irá desenvolver os seus ensaios filosóficos e políticos. Em 1671 ele escreverá a primeira versão do Ensaio sobre o Entendimento Humano. Em 1689, seria publicada a sua segunda versão. Em 1690, por fim, seriam publicados os dois Tratados sobre o Direito Civil.

Em relação à ideia de origem da dicotomia entre igualdade e desigualdade humanas, Locke parte da ideia de que os homens, no seu estado primordial, eram felizes e iguais (LOCKE, 1998); no entanto, estes seres humanos organizados em sociedades precisaram ultrapassar o estado de natureza, uma vez que a vida em comum em uma sociedade mais complexa implicou na necessidade da introdução de um elemento de normatização e controle que corresponderia ao governo, ao poder legislativo e a uma série de instituições sociais (LOCKE, 1998). Mas ele não vê esta superação do estado de natureza com pessimismo ou com nostalgia (como Rousseau), e sim como uma necessidade. Para viver na sociedade civil, o homem teve de aprender a conviver e lidar com as desigualdades, mas ao mesmo tempo poderia e deveria empenhar-se em lutar contra as tiranias e em rejeitar os privilégios sociais adquiridos sem esforço (uma referência à nobreza ociosa do Antigo Regime). Para uma época que ainda respirava a densa atmosfera das monarquias absolutas, as proposições de Locke são bem progressistas. Se pudermos pedir licença ao uso de uma expressão um pouco anacrônica para esta época, poderemos entendê-las como a pedra angular do individualismo liberal, ou mesmo das futuras democracias liberais.

As ideias de Locke viriam a calhar para o tipo de capitalismo que àquela época se consolidava (ou, antes, suas ideias são produtos deste mesmo capitalismo). É assim que, por um lado, o filósofo inglês atribui na sua teoria uma centralidade ao trabalho (em oposição aos privilégios hereditários da nobreza do Antigo Regime). Por outro lado a sua teoria política legitima um novo conceito de propriedade que interessava à burguesia em ascensão. A igualdade a ser assegurada aos homens em estado de sociedade deveria ser mediada tanto pelo trabalho como pela propriedade privada. Vejamos como isto se dá em articulação a outros conceitos importantes do pensamento de Locke. 
Um dos elementos importantes desta teoria é a noção de direito natural, que para Locke (1998) corresponderia à ideia de que os homens teriam um direito primordial à vida, à liberdade e aos bens necessários para sua preservação. Este pensamento ancorava-se na já mencionada ideia de que os homens eram irredutivelmente livres por natureza (mesmo que houvesse diferenças relativas à força, à habilidade ou à inteligência). Ao serem impulsionados à superação do Estado de Natureza, os homens tiveram de se articular socialmente por meio de um Pacto Social (LOCKE, 1998). Esta passagem da vida natural para a vida social, contudo, não deveria implicar em perda essencial da igualdade primordial entre os homens, no sentido em que Locke entendia esta igualdade. Afinal, já era um corolário antigo que qualquer contrato ou pacto só tem sentido e validade se as partes contratantes forem livres e iguais, e se estiverem firmando o contrato de forma voluntária. Qualquer coerção no momento da associação (uma tirania, por exemplo) invalida necessariamente a ideia de contrato.

A noção de contrato social já havia sido empregada por Hobbes (2002), Mas este teórico do absolutismo a emprega para seus próprios fins. Ele enfatiza a ideia de que os homens - livres por natureza, mas depois reunidos em uma multidão de indivíduos que passa a constituir um "corpo político" - possuem o direito de transferir voluntariamente a liberdade a um terceiro: o soberano absoluto que a partir daí passa a ter legitimada a sua autoridade. Desta forma, em Hobbes, a principal função do contrato social é legitimar a soberania de um poder acima de todos para que, assim, estabeleça-se um controle sem o qual os homens (lobos de si mesmos) se aniquilariam reciprocamente. Este soberano criado artificialmente é o Estado - que pode ser tanto um monarca, uma oligarquia ou uma assembleia democrática. $\mathrm{O}$ fundamental é que este poder seja absoluto, no sentido de que seja exercido imperiosamente acima dos indivíduos (monopolizando, por exemplo, o controle da violência física por meio do exército e da polícia, a justiça por meio das instituições do direito público, ou ainda o direito de coletar impostos). É evidente que esta teoria cai como uma luva para a Monarquia Absoluta (que, em um mundo moderno, só com muita dificuldade poderia amparar-se nas tradicionais teorias de um direito divino transferido diretamente de Deus para um rei hereditário). A teoria de Hobbes [1647] (1974) permite amparar o poder da monarquia absolutista com um sistema que fala em uma combinação de direito natural e contrato, e não mais em uma combinação de direito divino e imposição vinda do alto. Mas o mesmo modelo poderia ser aplicado a uma estrutura republicana.

Se Hobbes utiliza esta argumentação para legitimar o poder absoluto, já em Locke, a principal função do pacto social é outra. Embora o Estado gerado pelo pacto social possua algumas atribuições que são similares às que lhe são atribuídas por Hobbes, a sua principal finalidade no sistema de Locke é na verdade a de assegurar o direito natural do homem à propriedade ${ }^{2}$ (LOCKE, 1998). Locke

\footnotetext{
2 "Propriedade" é utilizada por Locke não só para se referir aos bens de raiz, mas também aos bens móveis (LOCKE, 1978, p. 45).
} 
desenvolve uma argumentação na qual se imiscui a benevolência de um Deus todopoderoso que originalmente havia concedido ao homem o direito natural à propriedade como um produto legítimo do trabalho a que este seria obrigado ${ }^{3}$. A propriedade só é gerada, aliás, quando o homem mistura a um objeto, ou a um pedaço de terra, o seu trabalho. Os primeiros homens teriam criado a propriedade quando realizaram um trabalho sobre a terra, tornando-a produtiva da perspectiva agrícola, ou quando transformaram a pedra bruta em um objeto. Estabelecida esta propriedade primordial - "natural" porque concedida e até imposta pelo Criador agora cabia ao Estado gerado pelo pacto social esta função principal: a de assegurar aos proprietários mais este direito natural.

A argumentação de Locke sobre a mistura de trabalho e propriedade, esta sancionada pela vontade divina, legitima particularmente a burguesia - tanto por lhe assegurar o acesso e preservação da propriedade quanto por enaltecer o trabalho, em oposição a uma nobreza parasitária que ainda vivia de persistências dos privilégios feudais. Ao mesmo tempo, ao relacionar a igualdade humana com o direito a propriedade privada e com a obrigação de trabalhar para obtê-la, o sistema liberal de Locke acaba justificando também a desigualdade social que se expressa por meio da existência de pobres - uma vez que estes passam a ser vistos como trabalhadores incompetentes que não conseguem tornar-se proprietários.

De qualquer modo, o estabelecimento da propriedade como direito natural de cada indivíduo marca uma ruptura importante com o sistema de propriedade e governo implícito no Antigo Regime. A partir daqui passam a existir dois padrões legítimos de propriedade: de um lado, a propriedade simultaneamente individual e privada; de outro, a propriedade simultaneamente estatal e pública. Mas já não existe mais a ideia da propriedade como patrimônio pessoal de um monarca que seria senhor de todos os bens e riquezas do reino, e que por isso poderia dispor destes bens de acordo com a sua vontade absoluta.

Tal como se disse, as ideias de Locke foram bastante progressistas para a sua época - particularmente por desqualificarem qualquer governo imposto pela tradição ou pela força, e também por sustentarem que a legitimidade de um governo apoiavase no consentimento expresso dos governados. Confirmando as revoluções burguesas que haviam se dado na Inglaterra seiscentista, e antecipando o clima revolucionário que brevemente agitaria a França setecentista, o seu Segundo Tratado

${ }^{3}$ Já Hobbes, contrastando com esta ideia, asseverava que a propriedade inexiste no estado de natureza e que havia sido instituída precisamente com a formação da sociedade civil (HOBBES, 1974). Neste sentido, o governante poderia - se fosse necessário - confiscar propriedades individuais, o que em Locke não seria possível, já que a propriedade seria um direito natural concedido pela instância divina e que precederia o Estado e a própria existência do governante soberano. Por outro lado, é bastante curioso notar que Deus aparece na argumentação de Locke e não na de Hobbes, embora seja muito comum o erro crasso de se pensar que Hobbes tem algo a ver com a teoria do direito divino (na qual Deus teria escolhido cada governante por sua obra e graça). Nada mais falso, quem sustentava, na época, a teoria do direito divino era Robert Filmer (1588-1653). 
sobre o Governo Civil [1690] sustentou a legitimidade da deposição de governantes que não estejam cumprindo adequadamente as suas funções no estado liberal (por exemplo, a proteção da propriedade privada). Historicamente localizada, esta obra de 1690 cumpriu o papel de legitimar a deposição de Jaime II pela Revolução Gloriosa (1688), com base na doutrina do "direito à resistência" contra governos tirânicos ou incompetentes. Enquanto isto, o Primeiro Tratado sobre o Governo Civil já tinha se erigido como uma crítica severa e sistemática à obra $O$ Patriarca, de Robert Filmer [1680] (2010), que sustentava a teoria do direito divino.

Podemos agora focar mais especificamente a questão da igualdade no interior deste sistema. O sistema liberal de Locke propõe a todos a "igualdade em algo" antes de mais nada no pretenso direito à aquisição de propriedade privada. Associado à democracia, pode-se acrescentar a isto o direito de todos à escolha de seus representantes junto ao governo; e, mais modernamente, este item evoluiu para o pretenso direito de cada cidadão ser elegível. O discurso da "igualdade das oportunidades de trabalho" é também habitual, embora se saiba que em muitas ocasiões o capitalismo vive também da existência de uma margem de desempregados que contribuem tanto para valorizar o trabalho enquanto uma conquista que nem todos logram obter, como para permitir o barateamento da mãode-obra (já que o trabalhador das profissões menos privilegiadas é compelido a aceitar baixos salários por saber que pode ser eventualmente substituído por um desempregado). Outra igualdade apregoada pelo pensamento liberal, já desde Locke, refere-se à ideia de que todos devem possuir a mesma liberdade de pensamento, já que o Estado não deve intervir na consciência dos governados. Mas este aspecto também é falacioso, alguém poderia contra-argumentar, já que modelo liberal aceita que seja exercida censura nos casos em que alguém emita opiniões que ponham em risco o próprio Estado.

Ao mesmo tempo, e este é outro ponto capital, a teoria liberal propõe que se respeite a liberdade econômica de todos os proprietários privados, permitindo que eles negociem livremente. Ao lado disso, sustenta-se um direito de livre-organização onde tanto os proprietários privados como os trabalhadores não-proprietários teriam liberdade para criar as suas organizações de classe. Portanto, de acordo com este sistema, todos são iguais no direito a agir economicamente - o que se adaptava bem ao padrão de capitalismo que se consolidava na Inglaterra da época de Locke.

Conforme se vê, o sistema liberal de Locke prevê em tese a igualdade de todos em relação aos aspectos acima citados, mas na prática beneficia mais especialmente os que conseguiram se tornar efetivamente proprietários individuais. Essa concepção de igualdade tornar-se-ia, na verdade, o limite da Revolução Francesa e de outras revoluções burguesas. A fronteira que estas revoluções tiveram por intransponíveis foi precisamente a da propriedade privada, e sempre as propostas mais igualitárias ou radicais foram refreadas a seu tempo nos processos revolucionários que seguiram o paradigma da Revolução Francesa. De qualquer modo, apesar da sua influência e assimilação pelas revoluções burguesas posteriores, 
o modelo liberal não foi, obviamente, o único sistema de Igualdade que se expressou na modernidade por meio de práticas concretas ou de formulações imaginárias. Será oportuno contrapô-lo ao modelo proposto por Rousseau, apenas algumas décadas depois de Locke.

\section{Outra vertente: a lgualdade radical proposta por Rousseau}

Jean-Jacques Rousseau (1712-1778), nascido em Genebra, escreve a parte mais importante de sua obra na França setecentista que precede de algumas décadas o período revolucionário. Um dos aspectos mais conhecidos de seu pensamento é a ideia de que a sociedade, competitiva e autoritária, havia transfigurado o homem natural - o "bom selvagem" que teria vivido primordialmente em um mundo caracterizado pela inocência original (ROUSSEAU, 1973a). Situando-se como um crítico inconformado da sociedade, Rousseau é também precursor do pessimismo romântico do século XIX. Mas, ao mesmo tempo, tornou-se um modelo para alguns dos sistemas de pensamento que buscaram discutir a igualdade política. Rousseau, do ponto de vista modelar, é uma espécie de "paladino da igualdade". O Discurso sobre a Origem e os Fundamentos da Desigualdade [1753] constitui a obra que examina mais diretamente a questão, e posteriormente examinaremos aspectos relativos ao vocabulário deste texto. Interessa também um verbete do mesmo ano para a enciclopédia iluminista, e que se intitulou Discurso sobre a Economia Política [1755] (2003). Neste último texto, Rousseau (2003) já se mostrava preocupado com as injustiças que resultariam da desigualdade social. Para minimizar esta desigualdade, ele propunha antes de mais nada a igualdade de direitos e deveres políticos. Para assegurar igualdade de instrução - aspecto a que poucos estiveram atentos na sua época - preconizava educação pública para todas as crianças (curiosamente, propunha para esta educação um padrão de austeridade inspirado no antigo modelo espartano). Por fim, propunha em terceiro lugar, a integração de um sistema econômico e financeiro que combinasse os recursos da propriedade pública com taxas sobre as heranças e o fausto. Aqui, já aparece um padrão distinto do que vimos em Locke, pois o Estado preconizado por Rousseau deve interferir mais no sentido de corrigir desigualdades geradas pelas atividades econômicas e por diferenças patrimoniais.

A questão da liberdade também era fundamental para Rousseau, e esta se lhe apresentava como um bem ou um valor irredutível que todos deveriam possuir (portanto, como algo mais que deveria ser considerado em seu sistema de Igualdade). Encarava a liberdade como um direito e um dever ao mesmo tempo, e afirmava que, uma vez que todos nasciam homens e livres; a liberdade lhes pertencia - de modo que renunciar a ela corresponderia a renunciar à própria qualidade de homem (vimos que, em contraste a isto, os súditos no sistema de Hobbes deveriam transferir sua liberdade ao Estado soberano). Em Rousseau, percebe-se que a articulação entre liberdade e igualdade é fundamental, de 
maneira que nos aproximamos mais do ideário emblemático da Revolução Francesa, ao qual seria acrescentada a noção de fraternidade.

Assim, para um liberal inspirado na matriz lockiana, existe liberdade na medida em que se leve em consideração a desigualdade entre proprietários e nãoproprietários, sendo que a igualdade stricto sensu mataria a liberdade. De sua parte, para Rousseau o único fundamento da liberdade é a igualdade, de maneira que não há liberdade onde não existir igualdade. Percebe-se aqui uma primeira distinção entre a matriz igualitária de Locke e a matriz igualitária de Rousseau.

Se bem que difira em muitos aspectos de Locke e também de Hobbes, é também verdade que a obra mais conhecida de Rousseau - O Contrato social em alguns aspectos importantes não deixa de sintetizar ideias destes dois autores que, sem a catalisação de Rousseau, tenderiam a ser tão incompatíveis como o liberalismo em relação ao absolutismo. Assim, ao considerar que todos os homens nascem livres e iguais (ideia que já vimos em Locke), Rousseau encara o Estado como objeto de um contrato social (à maneira de Hobbes) mas no qual os indivíduos não renunciam a seus direitos naturais. Ao contrário, os indivíduos entram aqui em acordo para a proteção destes direitos, que o Estado é criado precisamente para preservar. Nesta função, o Estado representaria a "vontade geral" (ROUSSEAU, 2003). Se após o contrato social, previsto por Hobbes, quem governa é um soberano, para o qual foram transferidos todos os poderes, já em Rousseau, quem governa é o próprio povo, e o Estado é apenas o seu representante (esta ideia seria fundamental para as correntes igualitaristas que animariam a Revolução Francesa).

Ainda dentro deste âmbito existem outras questões importantes a considerar, e até mesmo algumas ambiguidades que se expressam no pensamento de Rousseau. John Locke e diversos iluministas, encarando a sociedade como um somatório ou uma convergência de indivíduos, haviam assumido que nas grandes questões deveria prevalecer como mais correta a opinião da maioria. Curiosamente, Rousseau questionou a aplicação para todas as ocasiões desta postura - hoje tida por mais democrática -, argumentando que os indivíduos que constituem a maioria podem, em muitos casos, desejar algo que seja contrário aos objetivos e necessidades do Estado para assegurar o bem comum. Ou seja, para Rousseau, a vontade geral (RIALS, 1988, p. 2) não deveria ser considerada mera soma dos indivíduos, mas sim como algo que os transcende. Napoleão Bonaparte, que durante a juventude fora um voraz leitor de Rousseau, teria visto a si mesmo como um legítimo representante da vontade geral, mesmo nos momentos de maior autoritarismo.

É dentro desta linha de pensamento que Rousseau afirma que a vontade geral deve dotar o Estado de força para que ele possa atuar em favor da Sociedade, mesmo quando isto signifique ir contra a vontade da maioria em alguma questão particular (aqui, a bem da verdade, Rousseau oscila sutilmente na direção de Hobbes). De igual modo, em certas passagens Rousseau deixa escapar 
proposições que facilmente poderiam ser associadas nos dias de hoje ao autoritarismo. Aparece por exemplo a proposição de punição de dissidentes com a morte, que foi mais tarde assumida na Revolução Francesa pelo terror. Por estas e outras de suas ideias, Rousseau seria tomado posteriormente como um modelo significativo para o igualitarismo jacobino, que se autolegitimou através de muitas ideias do filósofo suíço.

A frase rousseauniana mais modelar sobre a igualdade, registrada logo ao princípio de Do Contrato Social, dizia que "os homens nascem livres e iguais, mas em todo lugar estão acorrentados" (ROUSSEAU, 1973b, p. 28). Expressa-se aqui todo o inconformismo de Rousseau diante de uma sociedade que desviara os homens de sua liberdade e igualdade naturais. Este inconformismo - só que se afastando das tonalidades nostálgicas e revestindo-se de real ímpeto revolucionário - logo agitaria a França da época de Luís XVI. Da mesma forma, outra contribuição importante a destacar é o fato de que Rousseau foi o primeiro teórico moderno da assembleia popular, afirmando a ideia de que a assembleia é o único órgão soberano e apontando o caminho para uma prática que seria crucial durante o período revolucionário. Neste aspecto, Rousseau (2002) mostra-se mais uma vez como oposto a Hobbes, que no décimo capítulo do De Cives havia argumentado contra os inconvenientes da assembléia popular quando em confronto contra o poder único do rei, sugerindo que alguns dos principais defeitos no primeiro caso seriam a incompetência, o domínio da eloquência (facilmente factível de ser convertido em domínio da demagogia), e a formação de partidos que se tornam entraves à formação de uma vontade coletiva ${ }^{4}$.

A questão central, que permite contrastar mais claramente a matriz lockiana e a matriz igualitária de Rousseau, refere-se à posição que a propriedade encontra nestes dois sistemas. Para Locke, a propriedade era natural (sancionada por Deus), e a sua preservação era desejável. Para Rousseau, a instauração da propriedade privada teria constituído um ato violento e antinatural, e, uma vez que já havia sido instituída, o melhor que os homens poderiam fazer era lidar com ela de um modo que não gerasse demasiada desigualdade social. Sua descrição da instauração da propriedade é particularmente romântica:

\footnotetext{
${ }^{4}$ No sistema proposto por Rousseau, deixaria de existir a separação dos três poderes que Montesquieu tinha proposto no Espírito das Leis [1748] (1962), e que já existia na Inglaterra anteriormente. A distinção entre os poderes legislativo (parlamento), executivo (governo) e o judiciário (instituições da justiça) teria sido elaborada com a finalidade de limitar o poder executivo, que estava nas mãos do soberano. Na época, Montesquieu preconizava uma monarquia de tipo constitucional. Contra esta proposta, Rousseau negaria a distinção entre os poderes, visando afirmar acima de tudo o poder da assembleia. Não poderia existir um poder executivo distinto do da assembleia (do poder representativo). Esta proposta será retomada na ocasião da Revolução Russa, no período em que, nos sovietes, os poderes legislativo e executivo identificamse e o poder representativo mostra-se dominante. Rousseau, aliás, também foi o criador da expressão "comissário do povo", também utilizada pelos bolchevistas.
} 


\begin{abstract}
[...] o primeiro homem que, ao cercar um terreno, afirmou 'isto é meu', encontrando pessoas suficientemente estúpidas para acreditarem nisso, foi o verdadeiro fundador da sociedade civil. [...] Quantos crimes, quantas guerras, quantos assassinatos, quantas misérias e horrores teriam sido poupados à humanidade se alguém arrancasse os marcos, ou nivelasse os fossos, gritando aos seus semelhantes: "não ouçam este impostor, vocês estarão perdidos se esquecerem que os frutos são de todos e a terra não pertence a ninguém" (ROUSSEAU, 1973b, p. 265).
\end{abstract}

Mas é patente que Rousseau não previu nenhuma fórmula para reverter à existência de propriedade. A bem da verdade, ele também não consegue imaginar nenhuma fórmula de reversão positiva ao estado natural que idealiza como um patamar primitivo e mais puro da experiência humana. A sua postura é mais a de aceitar esse movimento irreversível da história humana que teria conduzido à sociedade civil, e a partir daí propor transformações que pudessem tornar a existência humana mais suportável. Seu sonho de retorno ao "bom selvagem" é assumido romanticamente, de maneira quase quimérica; mas, paradoxalmente, algumas de suas propostas reforçam o autoritarismo, e não é a toa que a "matriz Rousseau" tenha sido reapropriada em alguns aspectos por igualitarismos articulados a propostas autoritárias.

\title{
A assimilação combinada de Locke e Rousseau pelo pensamento burguês
}

A “matriz Rousseau", poderemos concluir, é complexa e não exclui alguns traços paradoxais. Ela intermescla prenúncios de um Romantismo nostálgico com antevisões do igualitarismo jacobino - atuante, violento e autoritário - mas, também, algo da imaginação utópica que iria grassar no século XIX. Por outro lado, a "matriz Rousseau" admite traços arcaicos ocultos nos sonhos de retorno ao "paraíso perdido" do estado natural, ao mesmo tempo em que tenta sistematizar um austero sistema educacional bastante moderno para a sua época.

Enquanto isto, a "matriz Locke" tornou-se a pedra angular do pensamento liberal. Ela legitima a propriedade que a "matriz Rousseau" tratara como um desvio. Por outro lado, assume a desigualdade social como um mal necessário que, destarte, deveria ser minimizado pelas igualdades relativas voltadas para algumas "variáveis focais" como a liberdade de ação econômica, as oportunidades de venda e compra da força de trabalho, ou o direito de escolha dos representantes políticos. A igualdade de todos com relação ao direito de agir economicamente (portanto um combinado de igualdade e liberdade voltado para um campo específico) é uma das variáveis focais que encontrou mais franca

\footnotetext{
${ }^{5}$ O conceito de "variável focal" como uma especificação que tenta responder a questão "igualdade de que" foi proposto por Amartya Kumar Sem (2001) em seu livro Desigualdade reexaminada.
} 
assimilação. Ela seria re-encaminhada pelos economistas setecentistas, e encontrou uma feliz expressão na frase de Gournay: laissez faire, laissez passer ("deixe fazer, deixe passar"). Adam Smith, de sua parte, deslocaria este mesmo combinado de igualdade de oportunidades e liberdade de ação para outra variável focal - o trabalho, que se expressaria como um trabalho livre, sem intervenções, guiado espontaneamente pela natureza. Eis aí a "matriz Locke", adaptando-se aos novos padrões do liberalismo e à constante reatualização das necessidades capitalistas.

Cada uma das duas matrizes que examinamos até aqui foi, a seu modo, assimilada pela Revolução Francesa e por outras revoluções burguesas. Mas, para além do agitado quadro dos movimentos sociais dos séculos XVIII e XIX, a "matriz Locke" difundiu-se comodamente pelo mundo das monarquias parlamentaristas e das democracias liberais, assim como também a "matriz Rousseau" foi relativamente assimilada nos tempos que se seguiram - por exemplo, pelos padrões de organização de assembleias nas instituições políticas e sindicalistas, deixando algumas marcas nas primeiras experiências de socialismo real.

Também podem ser buscados na história subsequente das ideias políticas os pensadores que tendem a uma destas tendências, ou que em alguns casos as combinam. Escrevendo na Inglaterra de meados do século XIX, John Stuart Mill (1806-1873) aprimora o liberalismo herdado de Locke e o direciona para uma aspiração mais democrática, temperando-o ao seu modo com algumas preocupações sociais que em algumas ocasiões parecem aproximá-lo, também, da "matriz Rousseau" (na verdade, a sua influência nesta última direção passa pelas ideias socialistas de Saint-Simon). A preocupação de John Stuart Mill com o destino das classes oprimidas é bastante nítida, e ele chega a defender a ideia de que a indústria incorporasse mecanismos de co-participação dos trabalhadores nos lucros. Ao mesmo tempo, radicaliza a proposta liberal de "liberdade de expressão", e revela francamente a preferência por um mundo liberal em que, tanto quanto possível, fosse acolhida a diversidade humana e o pluralismo de ideias. Por fim, incorpora uma preocupação que ainda não havia sido abraçada pelo liberalismo tradicional: a extensão do direito de voto às mulheres. Desta forma, a discussão liberal da Igualdade avança aqui para um campo que só seria realmente ocupado no século XX.

Abordando mais especialmente o próprio movimento revolucionário de 1789 - por tantos considerado como o grande divisor de águas em termos de extensão da noção de igualdade aos âmbitos jurídico e político - este mostrou uma assimilação imediata das duas matrizes ("Locke" e "Rousseau") devidamente combinadas. Assim, a Declaração dos Direitos do Homem (RIALS, 1988), elaborada pouco depois da Tomada da Bastilha, apresenta-se como uma combinação da "matriz Locke" com a "matriz Rousseau". Partindo no 'Artigo 1' da ideia de que "os homens nascem livres e iguais" (ponto comum entre os dois 
filósofos), os principais pontos do liberalismo lockiano são em seguida convertidos em direitos humanos inalienáveis - destacadamente os direitos à propriedade privada, à liberdade (lato sensu), à prosperidade, ao livre agir econômico, à liberdade de consciência e à expressão (ressalvando-se os casos de ameaça ao poder constituído, tal como propunha Locke). A "teoria da resistência" proposta por Locke é sintetizada em "direito à resistência à opressão" ("Artigos 2 e 11') (RIALS, 1988, p.1-3). Da mesma forma, são assimiladas claramente as marcas discursivas de Rousseau, com referência direta à vontade geral ('Artigo 6' - "A lei é expressão da vontade geral"). Assim, pode-se dizer que a Declaração de Direitos do Homem assimila os principais pontos de conteúdo difundidos pela "matriz Locke", e acrescenta-lhe aspectos discursivos da "matriz Rousseau".

A pronta assimilação das duas matrizes, enfim, mostra bem claramente como a noção de igualdade foi penetrando em novos espaços a partir do período moderno, tomando grande vulto no período iluminista. Ao mesmo tempo, ao imaginarem a igualdade em um sentido mais extenso - isto é, uma igualdade abrangente a todos os homens e integrando os âmbitos político e jurídico - alguns filósofos do século XVIII já começavam a intuir que não bastaria equalizar os homens nas leis escritas se isto não correspondesse a uma realidade social efetiva. Condorcet [1793] (1988), escrevendo do final do século XVIII, já reconhecia que "existe uma diferença entre os direitos que a lei reconhece aos cidadãos e os direitos que eles gozam em realidade". Percebia-se também que essa extensão da igualdade a âmbitos mais amplos também implicava em colocar em jogo, além da igualdade política e da igualdade jurídica, a igualdade social. Mas o adentramento mais sistemático deste último âmbito, conforme veremos, estaria muito mais presente no pensamento político do século XX. De qualquer modo, o próprio Condorcet já dava a perceber em 1793 que as igualdades política e jurídica poderiam ficar comprometidas caso não se atentasse para a "desigualdade de riqueza", para a "desigualdade de estado social" e para a "desigualdade de instrução".

De qualquer modo, as matrizes igualitárias que foram assimiladas após as revoluções burguesas - isto é, aquelas que se institucionalizaram, por assim dizer - referiram-se mais particularmente aos espaços jurídico e político, e foram assimiladas precisamente nos aspectos que favoreciam ao desenvolvimento da sociedade burguesa. Muitos dos filósofos iluministas, aliás, não reclamavam mais do que a igualdade civil perante a lei e o direito político de eleger representantes. No plano da Igualdade Social, poucos destes filósofos iluministas avançaram mais especificamente. Voltaire, por exemplo, chegou a considerar a desigualdade como "eterna e fatal".

Por outro lado, o mesmo século que gestou o pensamento iluminista gerou correntes de pensamento bem mais igualitárias, que também conseguiram sua representação no movimento revolucionário, embora a seu tempo estes movimentos também tenham sido reprimidos sem a mesma assimilação que 
beneficiou as matrizes iluministas. Examinaremos oportunamente algumas destas "matrizes igualitárias" - igualitárias em stricto sensu, e, conforme veremos, mais "igualitaristas" do que "igualitárias" (de acordo com uma delimitação conceitual que oportunamente será precisada).

Quando afirmamos que a grande conquista do século XVIII dá-se mesmo na consolidação de um imaginário da igualdade política e da igualdade jurídica, atentamos para o fato de que "imaginário" é mesmo uma palavra bastante adequada, uma vez que os ideais de igualdade continuaram a habitar, mesmo a partir desta época, muito mais a teoria do que a prática. A Revolução Francesa, por exemplo, acenou estrondosamente para as possibilidades de realizar simultaneamente a igualdade jurídica, a igualdade política e a igualdade econômica (ou a igualdade relativa ao espaço das condições materiais). A Constituinte (produzida no movimento revolucionário francês) - em sintonia com a Declaração de Direitos do Homem e do Cidadão na ideia central de que "os homens nascem e permanecem livres e iguais no direito" - teria realizado de maneira plena a igualdade jurídica, um tanto imperfeitamente a igualdade política, e fracassado claramente nas suas possibilidades de se aproximar de uma igualdade econômica.

De qualquer maneira, o que se conseguiu foi conquistado às custas de muitas colisões e hesitações. O ideal da igualdade entrechocou-se em diversas ocasiões com o ideal da liberdade, com o qual iria partilhar - juntamente com o ideal da fraternidade - o próprio lema central da revolução ${ }^{6}$.

\section{Duas perguntas fundamentais sobre a igualdade}

O contraste inicial entre Locke e Rousseau, indicativo da complexidade do tema, permite entrever as complexidades e ambiguidades que a noção de igualdade envolve. Autores diversos têm se empenhado em sistematizar esta diversidade. Uma boa baliza de sistematização para a compreensão dos sistemas que discutem a Igualdade, por exemplo, foi proposta por Norberto Bobbio na sua Teoria Geral da Política. Para o cientista político italiano, todo esforço no sentido de refletir sistematicamente sobre a igualdade deve partir inicialmente de duas perguntas fundamentais. Quando se começa a falar em igualdade, uma primeira pergunta é: "igualdade entre quem?", e, concomitantemente, pergunta-se de imediato: "igualdade em relação ao que?" (BOBBIO, 2000, p. 298-299).

A indagação "igualdade de que" pode ter vários desdobramentos que, utilizando uma expressão de Amartya Sem, poderemos chamar aqui de variáveis focais. Cada variável focal define um espaço ao qual se refere à igualdade

\footnotetext{
${ }^{6}$ Apenas para dar um exemplo, alguns historiadores levantam a questão de que na Revolução Francesa o dilema jacobino foi precisamente o de respeitar o direito à propriedade e correr o risco de perder o apoio das massas, ou de intervir na propriedade e consequentemente enfrentar uma oposição à direita, que só poderia ser solucionada com o recurso ao terror. Diante deste dilema, os jacobinos preferiram a igualdade à liberdade, e seus caminhos históricos são bem conhecidos.
} 
proposta ou pretendida. Pode ser proposta a igualdade de algo como a escolha de representantes, as oportunidades de trabalho, de instrução, e, no limite, a igualdade de tudo. Em seguida, deve-se ter em vista que as perguntas primordiais unidas ("igualdade entre quem" e "igualdade de que") podem se ramificar em quatro possibilidades de respostas que, segundo Bobbio, seriam as seguintes: 1) igualdade de alguns em relação a algo; 2) igualdade de alguns em tudo; 3) igualdade de todos em alguma coisa; e, 4) igualdade de todos em tudo. Será possível esquematizar este plano de categorias:

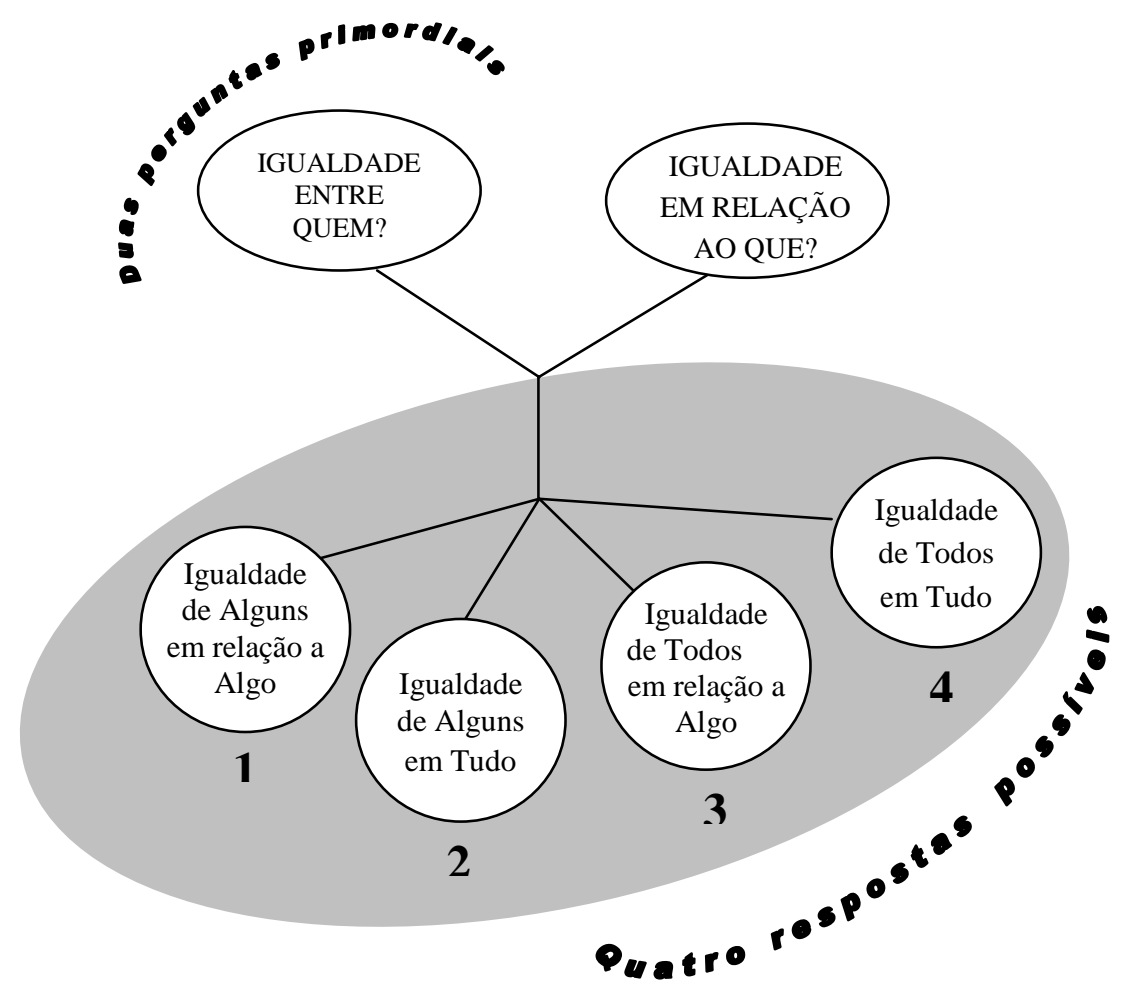

Fonte: Elaboração própria.

Os exemplos enquadráveis em cada um destes casos podem ser encontrados fartamente na história das ideias e na história de fato. Não vale a pena insistir na primeira possibilidade (igualdade de alguns em relação a algo). Tal como faz notar Bobbio (2000), este é o lugar comum de qualquer lei ou regulamentação. Toda lei refere-se a sujeitos ou pacientes que possuam algo em comum que os enquadre na situação específica de que trata a lei (e que desta forma correspondem apenas a um subconjunto do universo maior de cidadãos), e ao mesmo tempo a lei estabelece direitos ou penalidades relativamente a algum aspecto. Resumindo a questão, uma lei refere-se a indivíduos específicos com relação a um problema igualmente específico. 
A resposta número 2 já nos conduz à aventura humana do pensamento político. "Igualdade de alguns em tudo" era o que propunha Platão em República (PLATÃO, 1993). Platão era crítico do modelo político de sua própria pólis - a Atenas clássica que se transformara em uma democracia plena, incluindo amplos direitos políticos para a parte mais miserável da população (conservando obviamente a exclusão dos escravos, dos estrangeiros e, em nível à parte, das mulheres). A utopia platônica será um princípio oportuno para a discussão das matrizes igualitárias que geram, com aparente paradoxo, clivagens sociais internas dentro das quais a igualdade é repensada mais uma vez, ao mesmo tempo em que se tenta revestir a totalidade social de algum tipo de igualdade em sentido mais amplo.

\section{A desigualdade planejada: uma utopia platônica}

A utopia platônica apresenta dois traços bastante igualitários para a época: são eliminadas a propriedade e a família. A educação seria igual para todos aos 20 anos, mas aí se produziria um primeiro corte no igualitarismo inicialmente proposto. Platão imaginava que neste ponto, o sistema educacional promovido pelo Estado poderia começar a discriminar - com base em avaliações rigorosas das trajetórias individuais - o "tipo de alma" de cada um. O primeiro tipo ao abandonar o sistema integral de educação eram as "almas de bronze", que seriam mais grosseiras e por isto, a partir dos 20 anos, deveriam se dedicar à subsistência da cidade em atividades como a agricultura, artesanato e comércio. Os demais seguiriam nos estudos por mais dez anos, quando então ocorreria um segundo corte. As "almas de prata" - focadas na virtude da coragem e prontas a desempenhar com eficiência os ofícios da guerra - formariam uma nova classe: a dos "guerreiros", que cuidariam permanentemente da defesa da cidade. As "almas de ouro" seguiriam nos estudos, agora centrados na filosofia. Aos cinquenta anos, os que fossem bem sucedidos numa avaliação final passariam a ser magistrados, adquirindo a ciência da política e responsabilizando-se pelo governo da cidade.

A idealização de Platão, deste modo, aponta para uma possível igualdade primordial na repartição de bens, mas para uma bem calculada desigualdade no que se refere ao direito ao poder e ao saber. Como para os filósofos da Grécia Antiga saber é sabor, a formação de uma elite do poder e do saber também implicaria, podemos acrescentar já ao nível interpretativo, em uma elite do prazer. Além disto, a definição das almas como metais, menos e mais nobres, mostra, aí, uma bem articulada discriminação social, pois haveria um jogo desigual de prestígios aí envolvido. O princípio democrático quebra-se também, apesar de uma pequena capa que preservava a aparência de democracia: no exercício de sua função política e diante de grandes decisões a serem tomadas, os filósofosdirigentes primeiro lançariam mão da persuasão para convencer os demais cidadãos de suas decisões; mas falhando este recurso teriam todo o direito à 
utilização da força para fazer valer as suas decisões que, no fim das contas, seriam as mais justas de acordo com as expectativas platônicas.

A República de Platão pode lembrar a alguns as partições igualitárias de uma sociedade de formigas, que possuem as formigas-operárias, as formigasguerreiras, e uma formiga-rainha. Mas, neste caso, a formiga-rainha corresponde ao núcleo de filósofos dirigentes. Os aspectos igualitários ocorrem no interior de cada grupo funcional. Por outro lado, o grupo dos filósofos-dirigentes seria efetivamente aquele que teria tudo o que um grego considerava necessário para uma vida plena. Afinal, os atenienses da época sempre consideraram dimensões imprescindíveis da vida verdadeiramente plena o exercício da política e da filosofia, necessariamente amparados por um tempo liberado para o ócio criativo. No caso dos filósofos da utopia platônica, o tempo do ócio criativo poderia se estender à totalidade - ao contrário do que ocorria com os filósofos que viviam no mundo real das democracias atenienses, já que nenhum cidadão poderia deixar de ir à guerra e de comandar a administração de suas propriedades.

Conforme se pode ver, o modelo platônico opõe-se frontalmente à igualdade democrática que existia na Atenas da época - período em que os direitos democráticos haviam se estendido aos pobres e que, para Platão, havia permitido a livre proliferação de demagogos que eram hábeis em manipular a opinião pública despreparada em favor dos seus interesses particulares. Platão questionava a igualdade aritmética, em particular no que se referia à distribuição dos valores políticos. Para ele a igualdade deveria ser necessariamente geométrica - isto é, ser aferida em razão do mérito e da qualidade do tipo de contribuição para a sociedade. No modelo que ele radicaliza com a República - apesar dos traços igualitaristas que aparecem para todos no que se refere à ausência de propriedade e da família nuclear - pode-se dizer que, no limite, temos a fórmula do "todos os cidadãos são iguais, mas uns são mais iguais do que os outros". Poder-se-ia argumentar que isto corresponde mais rigorosamente a uma Distopia (uma utopia ao contrário). De qualquer forma, no interior de cada categoria funcional proposta pela utopia platônica realiza-se a fórmula do "igualdade de alguns em tudo".

\section{A Desigualdade Oculta e as Democracias Liberais}

A resposta número três ("igualdade de todos em relação a algo") recoloca-nos no âmbito das constituições liberais. O sufrágio universal, por exemplo, corresponde à ideia de que o direito de eleger representantes políticos através do voto deve ser extensivo a todos os cidadãos ou componentes de uma sociedade (ou quase todos, se considerarmos a exclusão de crianças e loucos). Temos aqui a igualdade de todos com relação a algo. Mas ao mesmo tempo uma sociedade liberal burguesa não prevê que todos tenham efetivamente direito à propriedade, por exemplo. Na verdade, o "direito à propriedade" - que vimos registrado na "matriz Locke" - corresponde essencialmente ao direito de preservar a propriedade já possuída e também à 
preservação dos meios de adquiri-la. Mas não significa que todos irão se tornar proprietários ou terão concretamente esta possibilidade assegurada.

$\mathrm{O}$ argumento pode ser distorcido, e um teórico liberal pode argumentar que na sua sociedade liberal e capitalista todos teriam direito a adquirir propriedades mediante a troca de dinheiro, e que todos teriam direito a adquirir dinheiro através da venda de seu trabalho livre. Mas isto, obviamente, seria uma falácia - e facilmente se pode perguntar pela existência efetiva de uma "igualdade de oportunidades" em uma sociedade liberal-capitalista. Inegavelmente, uma sociedade liberal ampara-se claramente em desigualdades de todos os tipos, sobretudo as mediadas pelo fator econômico. Mas, tal como vimos com o exame da "matriz Locke", o pensamento liberal sempre reserva um espaço focal onde a igualdade possa ser em tese proposta para todos, mesmo que no momento seguinte precise acrescentar um âmbito de exceções que rigorosamente exclui a igualdade ou a liberdade plena mesmo no espaço focal considerado. Por exemplo, admite-se igualdade de todos com relação à liberdade de expressão, ressalvando-se os casos em que esta liberdade de expressão possa ameaçar o poder constituído ou o próprio Estado liberal.

Por fim, a desigualdade imiscui-se de outras maneiras no programa de igualdades focais proposto pela "matriz Liberal". Para retomar o mesmo exemplo igualdade de todos relativamente à "liberdade de expressão", pode-se lembrar que se possuo uma caneta ou papel - posso exercer a liberdade de expressão através da escrita de uma maneira que não está franqueada àqueles que não possuem este objeto ou meios para adquiri-la. A caneta pode ser substituída por uma máquina de escrever, por um computador, por uma rede de jornais que alguém comande - tanto faz. E a isto se acrescenta que, de acordo com o seu nível de instrução (também passível de ser adquirido através de dinheiro, como a caneta, ou o papel) um indivíduo pode desenvolver mais competência para se expressar do que outro. $\mathrm{O}$ mesmo raciocínio pode ser estendido para aqueles que buscam trabalho considerando-se que terão mais oportunidades os que possuírem mais instrução, ou roupas que the assegurem uma melhor apresentação. Estas são as ambiguidades ocultas nas variáveis focais propostas desarticuladamente pela "matriz liberal".

A "matriz liberal" vive da ocultação da desigualdade da qual ela mesma se alimenta. Ela ampara-se no imaginário da igualdade democrática, ao mesmo tempo em que se sustenta na concretude da desigualdade capitalista. Também este mundo é crivado de marcas e processos de condicionamento diversos - a maioria dos quais desenvolvendo-se inconscientemente sem que mesmo os seus próprios interessados disto se apercebam. As manipulações superficiais e explícitas estão longe de constituírem os principais recursos de dominação, e entramos aqui em questões mais intrincadas como as da ideologia e da alienação. Ao contrário da República de Platão e do Mundo Novo de Huxley, no mundo liberal são ocultados os mecanismos de condicionamento e de clivagem social (e de manutenção da clivagem social). Da mesma forma, as arestas sociais são cuidadosamente aparadas, e a educação é 
proposta como universal e pública (mas na verdade assume um papel igualmente relevante na moldagem dos indivíduos, sem que estes tomem consciência disto). A família também internaliza muitas vezes os próprios processos de condicionamento: a natureza autoritária e hierárquica refugia-se na figura do pai, a desigualdade social dos sexos ali se instala. Os tempos reviram esta matriz conforme os movimentos capitalistas. Pode ser que as mães assumam o controle familiar, mas a hierarquia persiste, os casamentos monogâmicos encobrem por vezes alianças econômicas emparelhando indivíduos do mesmo tipo, o afeto é exposto na prateleira como se fosse uma mercadoria.

A desigualdade e os processos que a geram e perpetuam estão ocultos daqueles que os sofrem e daqueles que deles se beneficiam. E, no entanto, basta sair às ruas para perceber a desigualdade para muito além da inapelavelmente visível desigualdade econômica. Os preconceitos afloram, as falas dos passantes revelam discursos cultivados em diferentes níveis de instrução e de inserção social, os serviços públicos mostram maior eficácia nos bairros privilegiados, há buracos nos bairros pobres, os sistemas de saúde amparam e prolongam a vida dos favorecidos. A "matriz liberal" oferece este jogo de igualdade e desigualdade para além da fórmula que concede "igualdade a todos em algo". De resto, as democracias liberais não constituem o único modelo que elabora esta fórmula. Mas inegavelmente elas são hábeis no seu emprego imaginário.

\section{Igualitarismos: a História continua}

A resposta número 4 ("igualdade de todos em tudo") nos conduz às utopias e propostas igualitaristas. Não haverá possibilidade de examinar os imaginários igualitaristas da igualdade nos limites deste artigo, mas pode-se de passagem dizer que as duas respostas imediatamente precedentes ("igualdade de alguns em tudo" e "igualdade de todos em algo") correspondem, cada qual à sua maneira, a padrões igualitários de algum tipo. A República de Platão - uma "igualdade de alguns em tudo" - é uma utopia igualitária dentro dos limites a que se propõe (uma utopia com exclusão social daqueles que estão fora destes limites, e com clivagens sociais e funcionais específicas). Mesmo a "matriz Locke", dentro da perspectiva liberal, circula dentro de uma proposta igualitária ("igualdade de todos em alguns aspectos"). Quem negará que a declaração dos direitos do homem, carregada das mesmas ideias que vimos em Locke e temperada com um pouco de Rousseau, é um empolgante documento igualitário nos artigos que descrevem os direitos inalienáveis dos seres humanos? E por todo lado as democracias liberais amparam-se no imaginário da igualdade, mesmo que a sua base capitalista sustente-se amplamente na desigualdade.

Estes dois campos - república platônica e democracia liberal desenvolvem-se dentro dos limites igualitários. Mas o âmbito que deixaremos a uma reflexão futura refere-se ao igualitarismo. Há uma sutil diferença entre "igualitário" e "igualitarista". Se repararmos bem, existe um superlativo bastante 
significativo envolvido na passagem de uma palavra a outra. O igualitarismo propõe a plenitude da igualdade nos dois termos da equação: "igualdade para todos em tudo (ou quase tudo)". Agora, sujeito e objeto do processo de equalização são expandidos tanto quanto possível. Num limite, o sujeito da igualdade tende à unidade absoluta e desaparecem as classes sociais; no outro limite, o objeto da igualdade estende-se a todas as condições de vida, e sintomaticamente pode desaparecer a propriedade privada. Não é preciso que sejam atingidos estes limites mais extremos para que já seja pertinente falar em igualitarismo, mas de alguma maneira deveremos estar mais próximos a eles. A reflexão sobre os diversos modelos e matrizes igualitaristas, todavia, seria por demais complexa para ser abordada nos limites deste artigo.

\section{José D'Assunção Barros é Doutor em História pela Universidade Federal Fluminense; Professor-Adjunto da Universidade Federal Rural do Rio de Janeiro, e Professor-Colaborador do Programa de História Comparada da Universidade Federal do Rio de Janeiro. E-mail: jose.d.assun@globomail.com}

\section{Referências}

BOBBIO, Norberto. Teoria Geral da Política - a filosofia política e as lições dos clássicos. Rio de Janeiro: Elsevier, 2000.

CONDORCET. Esquisse d'un tableau historique des progrès de l'esprit humain. Paris: Flammarion, 1988 [1973].

FILMER, Robert. Patriarca o el poder natural de los reyes (edición a cargo de Ángel Rivero). Madrid: Alianza Editorial, 2010 [1680].

HOBBES, Thomas. Do Cidadão. São Paulo: Martins Fontes, 2002.

HOBBES, Thomas. Leviatã ou matéria, Forma e poder de um Estado eclesiástico e civil. São Paulo: Abril, 1974.

HILL, Christopher. O Mundo de Ponta Cabeça. São Paulo: Companhia das Letras, 1987.

LOCKE, John. Segundo Tratado Sobre o Governo Civil. São Paulo: Abril Cultural, 1978.

LOCKE, John. Dois Tratados sobre o Governo. São Paulo: Martins Fontes, 1998. MONTESQUIEU. O Espírito das Leis. São Paulo: Difusão Européia do Livro, 1962 [1748].

PLATÃO. A República. Lisboa: Fundação Calouste Gulbenkian, 1993.

ROUSSEAU, Jean-Jacques. Discurso sobre a origem e os fundamentos da desigualdade entre os homens. In: Os Pensadores - vol. XXIV. São Paulo: Abril Cultural, 1973a. p. 223-316. 
ROUSSEAU, Jean-Jacques. Do Contrato Social. In: Os Pensadores - vol. XXIV. São Paulo: Abril Cultural, 1973b. p. 7-205.

ROUSSEAU, Jean-Jacques. Discurso sobre a Economia Política. In: Rousseau e as Relações Internacionais. São Paulo: Imprensa Oficial do Estado, 2003 [1755]. p. 1-44.

SEN, Amartya Kumar. Desigualdade reexaminada. Rio de Janeiro: Record, 2001.

VOLTAIRE. Carta de Voltaire a Rousseau. Arca - Revista Literária Anual, Florianópolis, n. 2, p. 55-57, 1995.

Texto recebido em 13 de maio de 2012. Aprovado em 05 de junho de 2013. 